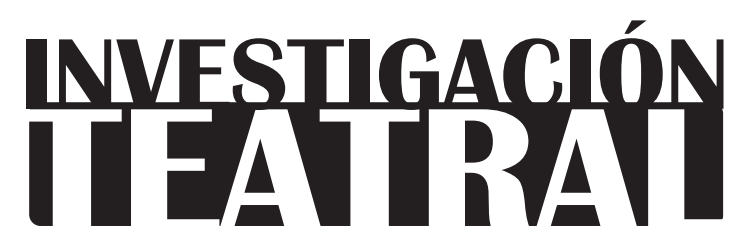

Revista de artes escénicas y performatividad

Vol. 10, Núm. 16

octubre 2019-marzo 2020

Segunda época

ISSN impreso: 1665-8728

ISSN electrónico: 2594-0953

Universidad Veracruzana

\title{
La exploración de un training cuerpo-mente del actor a través del butoh
}

\author{
María Angélica Zamora Chong*
}

\footnotetext{
* Organización Teatral de la Universidad Veracruzana, México.

e-mail: gelyzchong.teatro@gmail.com
}

Recibido: 15 de mayo de 2019

Aceptado: 16 de agosto de 2019

Doi: $10.25009 /$ it.v10i16.2614 


\section{La exploración de un training cuerpo-mente del actor a través del butoh}

\section{Resumen}

Esta investigación traza una ruta desde el origen del butoh y su alcance global (particularmente en su impacto y relación con México) hasta llegar a elementos esenciales que plasman la búsqueda vital de un camino a partir de técnicas derivadas de este género. Se ofrece un punto de partida y uno medio para conseguir un training (entrenamiento corporal) actoral mediante la exploración cuerpo-mente.

Palabras clave: Actuación, danza-teatro, formación actoral, ritual, Dance of Darkness, México.

\section{An Exploration of an Actor's Mind-Body Training through Butoh}

\section{Abstract}

This article describes Butoh's route from its origins to its global presence, from a Mexican perspective. The essential elements derived from Butoh's techniques can be understood as a vital search for a path. The article offers a starting point and a midpoint in body-mind exploration as part of an actor's training.

Keywords: Performance, dance-theater, acting training, ritual, Dance of Darkness, Mexico. 


\section{La exploración de un training cuerpo- mente del actor a través del butoh}

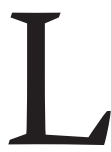

a vida se expresa como una búsqueda constante y el camino que se debe hacer es de primordial importancia: renovarse o morir. En el teatro sucede algo que va de la mano con esta idea, se requiere un aprendizaje que permita vivir en la escena. En cada ciclo, antes de llegar a ello, hay un proceso de gestación: la búsqueda del actor. Sin embargo, este proceso no puede pensarse finito, siempre hay que buscar aprender, tal como en la vida, incluso de manera más real. La búsqueda se da a través de un entrenamiento que permita vivir al cuerpo en escena, para que muera lo que no sirve. Entrenamientos y poéticas hay una infinidad, todos valiosos y enriquecedores, pero hay uno en particular en el que la vida y la muerte son esenciales, donde el cuerpo se vuelve camino y éste se vive a través del cuerpo. La danza butoh parte precisamente de estos elementos.

\section{Contexto e historia}

Para generar un training (entrenamiento corporal) a partir del butoh es necesario conocer el contexto en el cual surge esta danza, los alcances que ha tenido en el mundo y en México. Sus creadores, Tatsumi Hijikata y Kazuo Ohno, designaron a su arte ankoku butoh (donde bu significa danzar, toh pisar y ankoku oscuridad). Desde entonces se le conoce como "la danza de la oscuridad", un concepto que en la cultura occidental podría estar relacionado con el concepto de lo tenebroso. Para estos artistas japoneses, se refiere a una exploración en lo más profundo del ser. Su estética puede resultar algo 
INVESTIGACIÓNTEATRAL

Vol. 10, Núm. 16

octubre 2019-marzo 2020
La exploración de un training cuerpo-mente del actor a través del butoh

María Angélica Zamora Chong

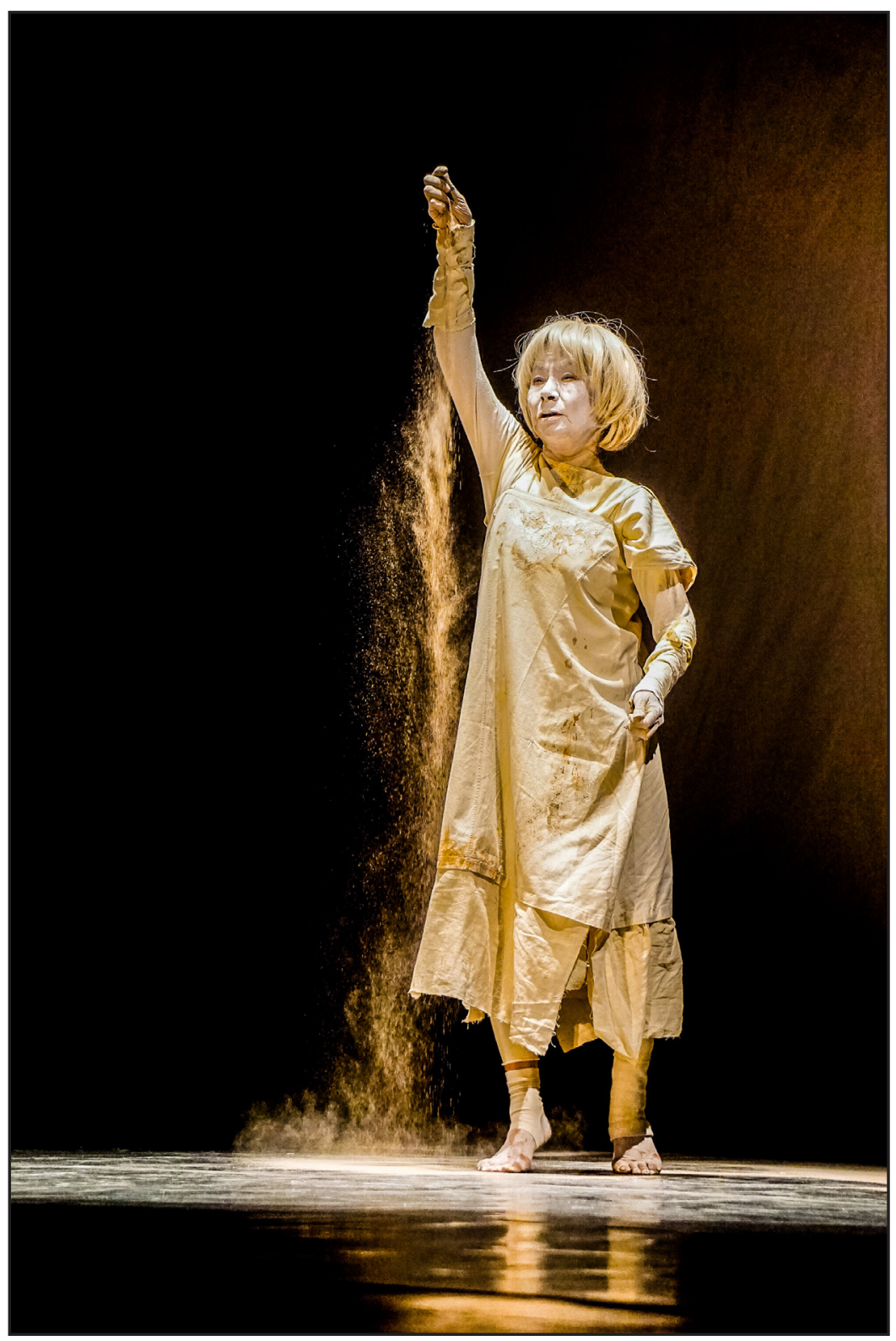

Natsu Nakajima en Like Smoke, Like Ash. $9^{\circ}$ Festival Emilio Carballido, Córdoba, Ver., 2017. Fotografía de Arturo Gamboa Rodríguez.

extraña para algunos ojos, pero no pretende necesariamente un entendimiento racional, sino una comprensión desde diversos niveles, como el sensorial. El butoh busca la provocación y la perturbación. Para Natsu Nakajima, creadora e intérprete discípula de Hijikata, el ankoku butoh "se basa en la creencia oriental de la unidad cuerpo-mente / cuerpo-corazón. Sostenemos la creencia de un cuerpo total y el concepto del 'cuerpo 
como la escenificación de la vida plenamente realizada" (Nakajima 5). ${ }^{1}$ El ankoku es la búsqueda del entendimiento de aquello intangible a través del cuerpo.

Actualmente, tiende a pensarse el ankoku butoh como aquel movimiento que se dio en el Japón de la posguerra, mientras que el término butoh suele referir a un género de danza-teatro que se desarrolla en todo el mundo y que incorpora la misma idea que llevaba el término ankoku. Para fines de este artículo, se entenderá al butoh como danza-teatro, sin abordarlo como un resultado escénico-estético, sino como un medio para la exploración actoral.

La naturaleza de este arte se basa en lo inacabado, y algo que influenció esta idea fue el hecho de que Tatsumi Hijikata muriera prematuramente, en 1986, sin haber terminado de definir qué era lo que buscaba. Por otro lado, Kazuo Ohno vivió y danzó hasta sus 103 años (falleció en 2010). El butoh nació de la conjunción de creencias entre estos dos grandes artistas.

Tatsumi Hijikata creció en el norte de Japón, se crió y trabajó en el campo; por tal motivo, su arte estuvo influenciado por la evocación de su infancia y por los movimientos de los cuerpos que trabajan en el campo. Al confrontar temas tabúes, quería experimentar la muerte, una y otra vez, en sí mismo. Creía que para poder gesticular la muerte había que morir de nuevo y que, aunque él no conocía la muerte, ella sí lo conocía a él (Dance of Darkness, entrevista).

Hijikata conoció a Kazuo Ohno en 1948, cuando lo vio bailar en un recital: "cortando el aire una y otra vez con su barbilla, causó una impresión duradera en mí... durante años esta danza-droga se quedó en mi memoria" (citado en MaGee párrafo 6). ${ }^{2}$ A partir de su encuentro, trabajaron juntos en la creación del butoh; Kazuo Ohno fue el mayor colaborador de vida de Hijikata. Ambos eran del norte de Japón.

Ohno tuvo que enlistarse en el ejército en 1938 y por nueve años permaneció en Manchuria y Nueva Guinea, donde fue prisionero de guerra y vio el horror que ésta ocasiona. A su regreso, retomó la danza y rara vez habló de sus experiencias durante el conflicto bélico: "yo llevo a todos los muertos conmigo", se limitaba a decir (citado en MaGee párrafo 7).

La primera obra butoh que salió a la luz se llamó Kinjiki o Los colores prohibidos, basada en la novela homónima de Yukio Mishima. Resultó ser una danza atrevida, que provocó el rechazo y menosprecio de mucha gente que la consideró una barbaridad. Solamente

1 Las citas de Natsu Nakajima corresponden a una ponencia que impartió en octubre de 1997. Se tuvo la oportunidad de acceder a dicha información gracias a un material proporcionado a la autora en un taller impartido en la Ciudad de México, en 2016.

2 "Cutting the air again and again with his chin, he made a lasting impression on me", Hijikata would later recall, "For years this drug dance stayed in my memory" (la traducción es mía). 
algunas personas la apreciaron, como el fotógrafo y cineasta Eikoh Hosoe, quien comenzó a colaborar con Tatsumi Hijikata en la realización de videos y fotografías a partir de haber visto Kinjiki, logrando que la gente en otros países pudiese asomarse al butoh por primera vez.

Hijikata tenía muchas razones para querer hacer algo tan contestatario, pues Japón se encontraba en un periodo de posguerra, después de que la bomba nuclear sacudiera la tierra y la consciencia, dejando cuerpos descuartizados que él describió como desgarrados o enteros, que flotan o caen. En el documental Dance of Darkness, realizado por Edin Velez, Hijikata menciona que los cuerpos del butoh son "cadáveres tratando desesperadamente de ponerse de pie" (entrevista).

Lo que siguió en la escena japonesa, después de la guerra, fue la llegada de formas occidentales de arte, llevadas por los estadounidenses, que hicieron que poco a poco se comenzaran a dejar de lado las artes tradicionales, como el teatro noh y el kabuki. Estas prácticas fueron reducidas a algo mecánico con el afán de buscar una "americanización" de las artes contemporáneas. Tales modalidades resultaban esquemas ajenos para Hijikata, quien se dio cuenta de que no encajaban con él ni con ciertos grupos que se negaban a la idea de imitar las nuevas formas que llegaban. Así que rescatando la esencia de un sentimiento de posguerra y ciertos elementos de las artes tradicionales japonesas (como la caminata del noh), y bajo la consigna de abandonar la domesticación y buscarse a sí mismo en medio de cuerpos mutilados, configuró el butoh.

Akiko Motofuji, esposa y colaboradora de Hijikata, comentó en Dance of Darkness: "él creó una danza que se desliza en la tierra, creó una danza adecuada para nuestro cuerpo" (entrevista). Sin duda, fue un arte contestatario que buscaba, como decía Hijikata, "regresar al cuerpo original... libre de la domesticación social" (citado en Nakajima 10). Así que el butoh, con elementos de misterio y grotesco, inició una búsqueda para romper las reglas y las formas establecidas, infringiendo toda forma de convención social.

El butoh nació después de aquellos hechos que dejaron sin habla y con ojos desorbitados a la gente: las bombas de Hiroshima y Nagasaki. Es una danza-teatro concebida como un arte total, en búsqueda del origen dentro de uno mismo; observa y comprende al mundo y sus acontecimientos para retarlos, perturbarlos, cambiarlos, sacrificarlos y, así, generar vida y muerte, un estado de pureza bello, pues para los japoneses las sombras son hermosas.

\section{Butoh en el mundo}

El butoh se enriqueció del expresionismo alemán y ése fue otro factor de vital importancia para su expansión. Kazuo Ohno se inspiró, por ejemplo, en las coreografías de la 
bailarina expresionista Mary Wigman y mantuvo una estrecha relación con Pina Bausch y su Tanztheater.

Hijikata y Ohno admiraban la obra de Jean Genet, además de que compartían las ideas de Antonin Artaud y su teatro de la crueldad sobre perturbar al público. Fue este ambiente de vanguardia el que impulsó al butoh hacia Europa, donde fue bien recibido y comenzó a ganar popularidad a finales de los años 70 y principios de los 80 . Paulatinamente, se introdujo en los Estados Unidos. En 1982, la compañía de Akaji Maro y Dai Rakuda Kan se presentó por primera vez en Nueva York, en varios festivales. Posteriormente, llegó también a esa ciudad la compañía Sankai Juku, dirigida por Ushio Amagatsu. Si bien varios solistas del género ya se habían presentado antes, el butoh provocó mayor impacto con el arribo de dichas compañías a Estados Unidos.

Akaji Maro fue actor de teatro y vivió en el estudio de Hijikata por tres años. Formó el grupo Dai Rakuda Kan en 1972, el cual aportó un aspecto dramático y amplió el espectáculo del butoh, gracias a la formación teatral de su director, aunque Hijikata había pensado al butoh como un teatro completo desde sus inicios. Natsu Nakajima explica:

Los críticos en occidente tienen razón al decir que el Butoh juega el rol de dos puentes: entre el teatro y la danza y entre la tradición y lo moderno. Hasta cierto punto, son juicios correctos, aunque muy periodísticos. En las artes escénicas tradicionales japonesas, como el Noh y Kabuki, no había distinción entre el teatro y la danza. Se interpretan como parte de un 'Teatro completo' y el Butoh tiene este mismo tipo de integración... Hijikata concibió al Butoh como el teatro absoluto (3).

Para Akaji Maro, esta danza-teatro es una oportunidad para que el cuerpo se revele a sí mismo en su rechazo a la superficialidad de la vida diaria. Esto puede observarse en los trabajos de Dai Rakuda Kan, permeados por el mismo espíritu de revuelta que estaba en el origen del butoh. La compañía hace un teatro de imágenes vivas, cuya idea ha evolucionado durante 40 años (es uno de las pocos grupos conformadas por los alumnos de Hijikata que han perdurado).

Otra de las compañías que se han mantenido hasta ahora -y que tuvo que ver con la inserción del butoh en diversos países en los años 70- es Sankai Juku, dirigida por Ushio Amagatsu, quien inicialmente fue integrante de Dai Rakuda Kan. Sankai Juku fundó una vertiente con una estética más limpia y coordinada de lo que este arte suele proponer, tendiendo a buscar el espectáculo en su obra como algo más coreográfico e, incluso, armónicamente demostrativo (a diferencia de Dai Rakuda Kan, que exalta la deformidad, la anarquía y la desesperación).

El hecho de que haya vertientes diferentes, no separa a estos artistas. Hijikata pasó por diversas etapas y obras, y esto hizo que sus alumnos vieran diversos aspectos en él y su 
arte. Se le ha preguntado a Akaji Maro acerca de estas diferencias y parece ser que es algo que no le preocupa a la hora de hacer arte:

El "estilo" en este sentido es sólo algo que se interpone en el camino, y todos queremos llegar al punto en que podemos trascender el "estilo". Pero cada vez que damos un paso en una nueva dirección, sólo volvemos rodeando. Así que siempre nos encontramos en una encrucijada, por así decirlo. Aun así, no es una cuestión de tratar de escapar de la situación, sino de abarcar el todo y seguir adelante mientras se crece y se expande de una manera esotérica. Creo que en el butoh hay una cuestión sobre dirigir el tiempo y el lugar, que al final significa cómo estar al mando de uno mismo ("Entrevista" párrafo 7 ). ${ }^{3}$

\section{Butoh en México y Latinoamérica}

La primera compañía japonesa en presentar un espectáculo de butoh en México fue Sankai Juku, en el Festival Internacional Cervantino de 1981, y causó un gran interés entre los creadores mexicanos. Como resultado, el director de teatro Abraham Oceransky gestionó que el mismo festival invitara a Kazuo Ohno en 1989. A partir de entonces se generó una colaboración directa con artistas japoneses de butoh. Abraham Oceransky y la bailarina Rocío Sagaón ${ }^{4}$ invitaron a Natsu Nakajima a impartir, por primera vez, un taller de butoh en Xalapa en 1989. Con el ideal de crecimiento e intercambio, Oceransky continúa invitando a diversos artistas (como Ko Murobushi, en 1998) para seguir con los primeros talleres en diversas ciudades del país, destacando entre éstas la de Xalapa, Veracruz.

3 ' $[. .$.$] 'style' in this sense is only something that gets in the way, and we all want to reach the point where$ we can transcend style. But every time we take a step out in a new direction it is only to return by some roundabout route. So we are always standing at a crossroads, so to speak. Still, it is not a matter of trying to escape from that situation, but rather to encompass the whole and move forward while growing and expanding in an esoteric sort of way. I think that in butoh there is that kind of question of commanding time and place, which in the end means how to be in command of yourself" (la traducción es mía).

4 Rocío Sagaón (Ciudad de México, 1933-Xalapa, 2015) fue una polifacética artista, destacada bailarina, coreógrafa, escultora y actriz. Perteneció a los ballets de Bellas Artes y al Popular de México. En cine, es recordada por su participación en la película Islas Marías (1950), al lado de Pedro Infante. En Xalapa expuso, con gran éxito, una serie de 17 piezas titulada Las malqueridas. (Ver Gómez, "Falleció Rocío Sagaón"). 
INVESTIGACIÓNTEATRAL

Revista de artes escénicas y performatividad

Vol. 10, Núm. 16

octubre 2019-marzo 2020
La exploración de un training cuerpo-mente del actor a través del butoh

María Angélica Zamora Chong

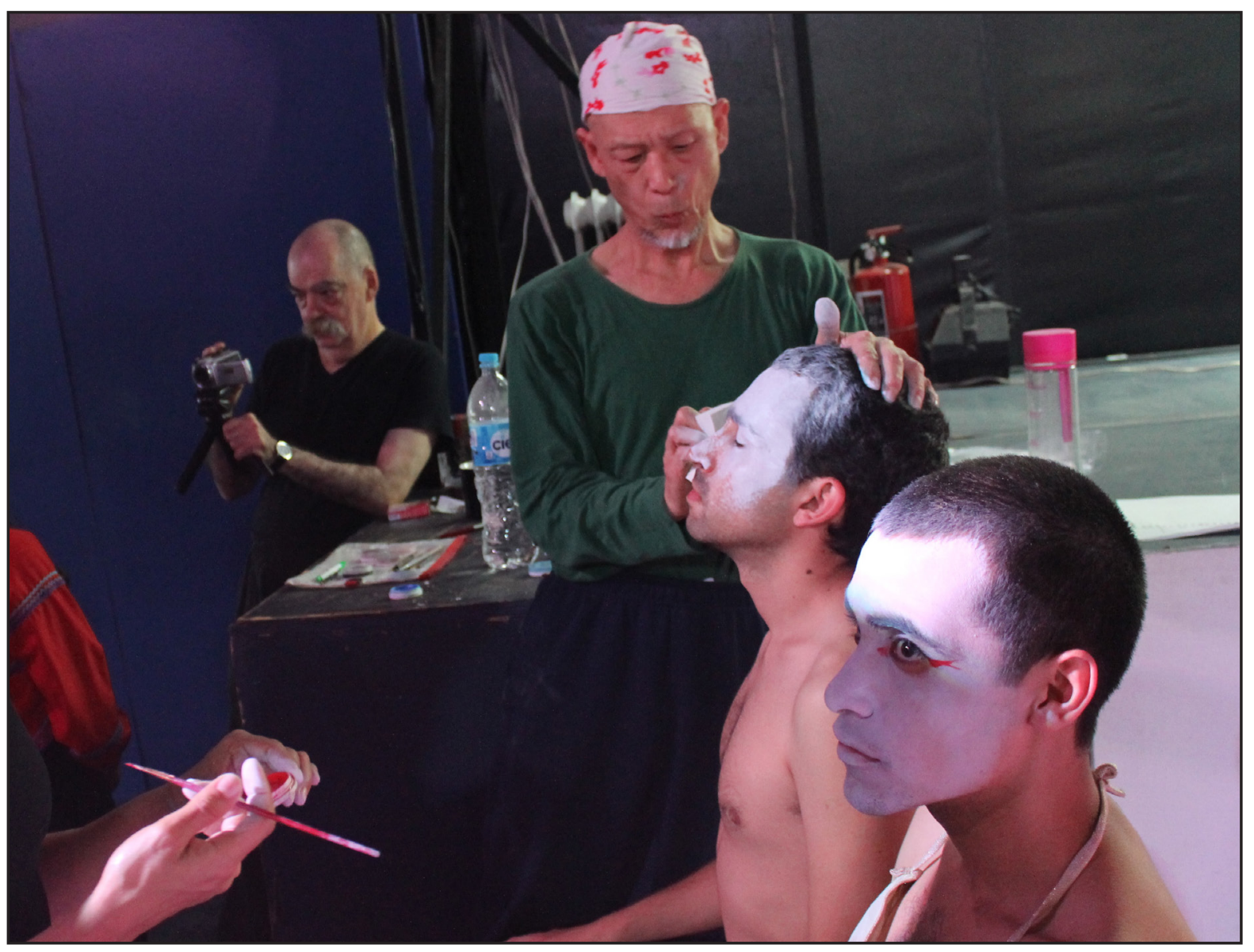

Abraham Oceransky y Katsura Kan antes de la presentación final del workshop. Teatro La Libertad, Xalapa, 2014. Fotografía de Angélica Zamora Chong.

La actriz argentina y catedrática de la Universidad Veracruzana, Laura Moss (Laura Moscovich Harus), inició en ese entonces su entrenamiento en butoh; luego, lo integró en su propia poética y lo conjugó con el flamenco. Con ello, trazó puentes entre ambas técnicas para ponerlas al servicio de la actuación y la formación de actores.

El desarrollo de esta danza-teatro en México provocó que cada vez más artistas indagaran en la transformación de sí mismos a partir de ella. Tal es el caso de Diego Piñón, uno de los máximos exponentes de butoh en el país, quien fue alumno directo de Kazuo Ohno y, en Michoacán, fundó Butoh Ritual Mexicano (donde, además del butoh japonés, investiga en torno a las tradiciones energéticas mexicanas, la danza ritual, la danza moderna y el teatro contemporáneo). Piñón imparte talleres en Canadá y Estados Unidos, países en los que se 
ha convertido en un referente respecto al enriquecimiento del butoh con otras culturas. Para los creadores japoneses, este tipo de encuentros dan lugar al crecimiento y a la trascendencia, como afirma en Dance of Darkness el alumno de Hijikata, Isamu Ohsuga:

Cuando viajamos a otros países, nos gusta encontrar la cultura de ese país. Las influencias se mezclan y se crea algo nuevo, otras culturas despiertan recuerdos ocultos en nuestros cuerpos. El intercambio cultural comienza con la incomprensión, pues no tenemos miedo a no comprender (entrevista).

El reconocer la incomprensión mutua entre culturas diversas transforma el encuentro hacia una apertura a la comunicación con uno mismo y el otro, impulsando la posibilidad del descubrimiento (apertura que es una de las principales características del butoh). El intercambio de culturas crea evolución. En Argentina, por ejemplo, uno de los grandes exponentes del butoh es Gustavo Collini Sartor, quien fue discípulo de Kazuo Ohno en Nueva York, en 1986, y que, desde 1994, ha desarrollado su Danza Butoh Argentina. En 1996 publicó el libro Kazuo Ohno: El último emperador de la danza, una de las pocas obras y referentes escritos en castellano acerca del butoh. Cabe destacar también la labor de Natalia Cuéllar en Chile, quien fundó la compañía Ruta de la Memoria y, a través del lenguaje del butoh, profundiza en temáticas de género y derechos humanos, además de que organiza el Festival Internacional Butoh Chile, que ya cuenta con tres ediciones (la última en 2018).

Actualmente, México se ha convertido en sede de varios festivales y encuentros de esta disciplina, que buscan unificar y ampliar su importancia en Latinoamérica, tales como el Encuentro Latinoamericano de Butoh ( $2^{a}$ edición en 2014), la Muestra Internacional de Butoh y Expresiones Contemporáneas en Guadalajara (desde 2014) y, a partir de 2016, el Festival Internacional de Danza Butoh en América Latina "Cuerpos en Revuelta", organizado por la compañía Laboratorio Escénico Danza Teatro Ritual (LEDTR), la cual es dirigida por Eugenia Vargas (bailarina cuya labor destaca por su exhaustiva dedicación a la formación, producción y promoción de este arte en México).

Gracias a los intercambios que se han dado desde los años 80 y al trabajo de los artistas que se dedican al butoh en el país, México se ha posicionado como uno de los máximos exponentes en este arte. Muestra también de esto es el actor y bailarín Espartaco Martínez, miembro de la compañía Dai Rakuda Kan, quien con esta agrupación ha participado en diversas obras presentadas en diferentes partes del mundo. En México coordinó una obra coreográfica entre la Compañía Nacional de Teatro y Dai Rakuda Kan para el Festival Internacional Cervantino de 2009, y también se dedica a realizar proyectos con comunidades marginadas del país. Es miembro fundador de la organización "Te O Tsunagu, México to Nippon", la cual busca la colaboración artística entre ambos países. 
A lo largo de la historia, diversos artistas de todo el mundo han viajado a México atraídos por su cultura, pues lo consideran un país surrealista, paradójico y enriquecedor. Yumiko Yoshioka (bailarina, coreógrafa y maestra de butoh), que ha dado talleres en México, afirma:

La gente de aquí tiene un cuerpo muy intuitivo... la tradición de la cultura mexicana está muy cerca de la naturaleza y del cosmos. Creo que la cultura mexicana también está sufriendo la sociedad moderna y quiere regresar cada vez más a la naturaleza del cuerpo, a lo natural: por eso el Butoh ayuda al mexicano (citada en Segura 34-35).

México también tiene cadáveres descuartizados, cuerpos enterrados que buscan ponerse de pie para ser encontrados, caras arrancadas en vida, sonidos de balas, palabras vacías, palabras no dichas, una conexión latente y visceral con la muerte desde tiempos ancestrales, así que no es de extrañar que el butoh tenga un enorme magnetismo con esta nación. En la actualidad hay nuevos artistas mexicanos que continúan con la exploración a través del butoh, pues éste genera un cuerpo y un lenguaje universal que se ha impregnado de una manera impresionante en el país. Como menciona Mark Holburn en el documental Dance of Darkness: "El butoh es como un virus expandiéndose a través del mundo, se volverá global. Gente en diferentes países lo va a incorporar dentro de sus cuerpos" (entrevista).

\section{El training y la posibilidad de auto-exploración y auto-observación}

Una de las razones por las cuales el butoh está siendo adoptado y explorado en muchos países es que permite la búsqueda interna del artista. Parte de la herencia de Tatsumi Hijikata es la idea de auto-exploración, para él el butoh no es algo que se practica sólo en un estudio, sino que se convierte en un modo de vida. Incluso en su lecho de muerte, Hijikata danzó hasta su último aliento, al igual que Kazuo Ohno quien, aun cuando había perdido la movilidad de su cuerpo casi por completo, siguió plasmando mundos con sus manos hasta sus últimos días.

Hijikata dejó como legado la posibilidad del auto-descubrimiento, a partir de lo cual el artista debe encontrar la congruencia consigo mismo. Esta idea de auto-exploración se puede llevar a la práctica a través de un entrenamiento actoral, aunque la palabra "entrenamiento" suele resultar demasiado básica respecto al trabajo del actor, ya que remite inmediatamente al ejercicio físico, la gimnasia, el deporte o incluso a la milicia, como sugiere Josette Féral en El training del actor. Se entrena para perfeccionar algo, lograr un virtuosismo, pero el entrenamiento de un actor necesita ser concebido más allá de la idea del ejercicio. Es por eso que, 
a partir de la década de los años 80, autores como Eugenio Barba emplean la palabra training, ya que su uso se enfoca en el trabajo actoral. Más allá de razones lingüísticas, el término training traspasa barreras culturales y hace que su significado sea universal, especializando de manera más puntual su uso para aludir a la disciplina escénica.

El legado de auto-exploración que dejó Hijikata en el butoh ofrece la posibilidad de entrar en caminos desconocidos, de la misma manera que el training busca un descubrimiento interno, en el que cada cualidad va cambiando al superar las limitaciones del artista, permitiéndole indagar en campos donde tiene que trabajar. Es ahí donde radica la auto-observación.

El actor, con su cuerpo y su ser, está en constante evolución, por lo que la disciplina se concibe de manera constante. No se circunscribe a una puesta en escena específica o a la formación, el training debe mantenerse continuamente y con entrega para lograr un autoconocimiento. Al respecto, Josette Féral, profesora de la Universidad de Quebec en Montreal, afirma:

El actor debe tomarse el tiempo necesario. Presente desde el inicio del aprendizaje, el verdadero entrenamiento se sigue toda la vida. Debe concebírsele como una 'formación continua' para que de verdad le permita al actor, a la manera del músico o el bailarín, mantener su instrumento (físico y psíquico) en buenas condiciones, es decir, en estado de creatividad. En consecuencia, el entrenamiento ya no está necesariamente ligado al espectáculo. No se le concibe de modo funcionalista... Más que el resultado, lo que importa es el proceso mismo (24).

Un training a partir del butoh puede constituir un camino de profundidad, evolución y entrega, en un diálogo con el propio cuerpo, con uno mismo, el espacio y el tiempo. La incertidumbre y la posibilidad, el peligro y la búsqueda de precisión, forman parte de este camino que estudia la preparación constante del terreno para la creación, dejando ir lo que no sirve (las formas impuestas, lo preestablecido), volviéndose un modo de vida.

Para Jerzy Grotowski, el training consiste en una preparación del actor para su oficio, pero también se vuelve un medio para alcanzar una plenitud personal y para obtener una inteligencia física. En su técnica, Grotowski busca una no técnica, pues el tipo de formación que propone consiste en "una vía negativa, no una colección de técnicas, sino la destrucción de obstáculos. Años de trabajo y de ejercicios especialmente elaborados para ello permiten a veces que se descubra el inicio del camino" (11). Existe una gran correspondencia entre el butoh y esta idea, pues se trata de dejar que se disuelvan los bloqueos. Cabe destacar, también, que es la técnica la que sirve al actor y no al contrario, pues para cada cuerpo y ser hay una línea personal, de manera que la ruta es el actor mismo. El training a partir del butoh permite que cada actor encuentre lo que le es adecuado. 


\section{Training físico y training mental}

La auto-exploración debe estar presente para lograr una expresión del cuerpo y la mente. La ideología que cada cuerpo refleja también debe cuidarse. En una entrevista realizada en 2012, Akaji Maro dice: "el cuerpo de cada uno es una obra en sí, ¿cómo revivir o hacer más consciente a tu cuerpo y a tu pensamiento? Desde ahí comienza la formación del actor" ("Entrevista con Maro Akaji").

El cuerpo es el lugar donde el actor logra cada conexión y transformación, el único hogar que se tiene como ser humano -que para el artista escénico se vuelve un templo-. Para el butoh, como ya se mencionó, cuerpo y mente no están separados: uno no existe sin el otro. No guardan entre sí una relación vertical o jerárquica -como suele verse en Occidente, dando más importancia a una u otro-, sino horizontal -como suele ser para los orientales-, teniendo ambas cosas la misma importancia. Fuera del cuerpo, la mente no tiene un lugar de desarrollo; sin la mente, el cuerpo no tiene posibilidad de exploración. Ambos deben estar relacionados para generar movimiento y acción. El camino del actor consiste en la investigación profunda de la unidad cuerpo-mente en sí mismo, para lograr la trascendencia. Un actor que dé mayor o menor importancia a uno u otro -en menosprecio de su totalidadestará limitado en escena, ya que ésta se vive a través de dicha unidad.

La inteligencia física se da entonces a partir de un training físico y un training mental. La mente en el butoh no se entiende sólo como pensamiento racional. Si bien en el teatro occidental se entienden las cosas a un nivel intelectual, el butoh trabaja, además, en otros niveles, muchos de ellos más etéreos e intangibles, pues de hecho la mente racional puede ser un impedimento a la hora de actuar y danzar.

Resulta que pensamiento e imagen mental no son lo mismo: el primero es crítico y lógico, mientras que la segunda no necesita ser lógica. La imagen no sólo se articula en la mente, traspasa ese nivel para producirse en todo el ser. El actor no debe tener miedo a otro tipo de inteligencia y entendimiento. Si bien el análisis y comprensión racional de una obra o del tema a tratar es algo básico para el trabajo actoral, esto no garantiza una buena actuación. En el training, la mente debe disponerse en diversos canales para evocar la imagen y la energía. A propósito de esto, el actor japonés Yoshi Oida (miembro de la compañía de Peter Brook) menciona:

Concentrarse demasiado en la inteligencia consciente y la técnica analítica puede limitarnos. Hemos de ser conscientes de que hay otras posibilidades ocultas. Sin esta consciencia más amplia, no podemos obtener fuerza más allá de nuestro estado normal en la vida cotidiana. No podemos evocar este tipo de energía (Oida, Los trucos del actor 31). 
La mente tiene posibilidades extraordinarias que deben ser exploradas. Un pensamiento racional, impuesto por falsos criterios de inteligencia, hace que el actor se auto-limite, lo cual resulta fatal para el teatro. Por otro lado, el uso del cuerpo restringido al mero virtuosismo, vacío y carente de contenido, se vuelve superficial, generando un teatro intrascendente.

En el teatro, cada movimiento es una danza, volviéndose acción que a su vez plantea un discurso y genera diálogo. Un training a partir del butoh permite al actor comprender cómo cuidar la mente y el cuerpo, ya que teatro y danza se vuelven un conjunto orgánico. Es así que un training físico y un training mental deben estar constante y activamente presentes, propiciando ambos una auto-observación que permita lograr un equilibrio entre ambos aspectos, y generar un "instrumento" totalmente dispuesto para la creación.

\section{Elementos y herramientas del butoh para el training del actor}

Los elementos que se plasman a continuación son esenciales para la búsqueda continua del actor en sí mismo hacia el auto-conocimiento, permitiéndole desarrollar su arte:

\section{- Limpieza de bloqueos: el vientre materno, el nacimiento y el aprender a ser nada}

Se habló al inicio de que el actor pasa por un proceso de gestación, idea que se relaciona en gran medida con la propuesta del butoh. El retorno al vientre materno es una búsqueda que éste emprende constantemente, complementando la idea de oscuridad planteada por el ankoku butoh. Cuando estamos en el vientre de nuestra madre, nos encontramos en el lugar más íntimo que conoceremos en toda nuestra existencia, al cual siempre anhelaremos volver después de nuestro nacimiento. En el butoh, el vientre materno significa profundidad. Muchos de los movimientos en esta danza inician a partir de dicha imagen y, aunque no parecen tener sentido, evocan sensaciones que nos remiten a un origen, a la recuperación de nuestro cuerpo y a un estado de plenitud que yace dentro del vientre materno:

No estoy interesado en una danza muy estructurada. La danza es una forma de vida, no una organización de movimientos. Mi arte es el arte de la improvisación. Esto es peligroso. Trato de llevar en mi cuerpo todo el peso y el misterio de la vida para seguir mis recuerdos hasta alcanzar el útero materno (Ohno, Dance of Darkness, entrevista).

La idea del vientre materno se traduce en regresar al cuerpo original, lo que equivaldría a un nuevo nacimiento para el actor. Éste vuelve a nacer todos los días, muriendo y renaciendo constantemente, repitiendo cada vez ese ciclo natural. El training sirve para quitar los 
bloqueos que estorban, el actor es responsable de trabajar en ello cada día para poder estar presente en la escena. Se debe vaciar de mente y cuerpo tantas veces como sea necesario; volver a ser nada para ser todo.

La nada es un concepto que se trabaja en butoh de manera muy profunda: se busca ser nada para eliminar el ego, ya que éste no permite ser algo fuera de uno mismo, ni mucho menos una comprensión de la naturaleza. Yoshi Oida menciona que cada día debe llevarse a cabo una purificación en el actor; tal como uno se lava diariamente los dientes, también el espíritu necesita un cuidado cotidiano: "no es suficiente ser el mismo que somos todos los días; hemos de purificar nuestra existencia de manera que nuestra comunicación trascienda y sea entendida por el receptor" (Los trucos del actor 37).

El actor se renueva al nacer diariamente y, al ser nada, se trasciende, lo cual se puede dar en un tiempo indefinido. Las tensiones y bloqueos que no le permiten una congruencia consigo mismo son limpiadas o eliminadas (mientras que, si un actor no se comunica consigo mismo, difícilmente podrá hacerlo con el espectador). Hay que purificar la existencia para que la energía fluya dentro del actor y traspase los bloqueos del público, dándole la oportunidad a ambos de volver al vientre materno a través de la escena.

\section{- Coherencia energética}

La energía suele ser un concepto complicado, pues muchas veces se le trata de manera muy compleja y otras burdamente (por ejemplo, pensando que la energía es meramente vigor, rapidez o tensión). Según Abraham Oceransky, "la energía es cuando lo de adentro y lo de afuera están conectados" (entrevista), es decir, aparece cuando hay una relación de fluidez y coherencia del actor consigo mismo, una conexión entre la mente y el cuerpo. En esa condición, el actor es capaz de comunicar lo que quiere y estar en el estado que busca, pues tiene una consciencia más amplia. Si un actor no tiene esa conexión, el espectador difícilmente podrá conectar con él. Es la coherencia energética del actor la que hace que éste pueda mover realidades, crear mundos y personajes. Sin ella, al estar en el escenario se verá sin fuerza, dejado, sin presencia, y solamente mostrará su ego (entendido como el apego a lo cómodo o lo conocido, que ancla al actor en el narcisismo y no le permite ir más allá). Es por eso que en el butoh se busca ser nada, entrar en un estado de profundidad que genere una sensibilidad del actor consigo mismo. Todo esto se logra mediante la auto-percepción y auto-exploración que posibilita la disciplina a través del training. Laura Moss busca un constante trabajo de auto-observación, puesto que "si el actor no es un instrumento sensible, si el actor no está conectado, no va a haber un teatro que conecte" (Moscovich, entrevista).

La energía es lo que da al actor la capacidad de producir algo en el público. Un actor entrenado debe ser capaz de manejar la energía propia y de modificar, así, la energía del 
espacio y el público. Al profundizar en el training con la coherencia de este elemento, comienza la trascendencia y el camino hacia la transformación.

\section{- Encarnación de la imagen}

Al lograr este auto-conocimiento se es capaz de buscar la transformación, que en el butoh se da también a partir de la imagen. Ésta no se queda sólo en la mente, sino que traspasa barreras, encarna. La mente y el cuerpo van en conjunto a lo largo de la exploración. Ejemplo de esto es que muchas veces la creación o el movimiento en el butoh comienzan a partir de premisas sencillas, como sucedía en el taller llamado "Butoh Body Resonance", impartido en Xalapa, en 2012, por Yumiko Yoshioka.

Yoshioka mostraba un movimiento sencillo, básico en el butoh, consistente en una ondulación que partía del tánden o hara (un punto energético abajo del ombligo, centro de gravedad del cuerpo humano que para los orientales representa el núcleo del ser en su totalidad). Una vez ubicado este punto, el ejercicio consistía en lanzarlo hacia atrás y bajar flexionando las rodillas muy levemente, creando así una ondulación a lo largo de la columna, de cóccix a coronilla. Yoshioka dijo que esto era una ola en el mar, y que eso se debía ser al hacer la ondulación. Posteriormente, con las rodillas flexionadas mostró un segundo movimiento, iniciado también a partir del hara, que iba de arriba a abajo en movimientos cortos y continuos. En seguida tomó una botella de agua que había junto a ella, la sacudió de arriba hacia abajo en un mismo eje y dijo que esa era la imagen: ser botella con agua adentro. Lo que ocurrió después fue que el movimiento comenzó a ser más fluido, pues la imagen afecta en la densidad del cuerpo. En el movimiento, la imagen siempre es necesaria y en butoh suelen usarse imágenes de todo tipo: agua, aire, fuego, metal, bicho, bruja, etcétera. Los maestros no dicen "representa la imagen" o "proyecta la imagen", ellos simplemente dicen: "sé agua, sé tierra, sé..." En el butoh la imagen no se representa, se encarna. El actor deja de ser él mismo, para poder ser algo más allá de sí mismo.

Esto genera un cambio de intención, diferente al de obedecer una orden o consigna impuesta externamente (donde existe un esfuerzo extra que impide fluir a la energía entre la mente y el cuerpo). A la hora de actuar, ese tipo de pensamiento se vuelve ego, pero si en lugar de ello se es, se genera una conexión diferente en el actor y se crea una disposición mayor porque el actor quiere que eso ocurra. Así se facilita la encarnación de la imagen, porque se da a partir de la vía del placer. En un training a partir del butoh, cada movimiento es acompañado de una imagen a manera de premisa. La exploración en las imágenes permite que la mente del actor se mantenga en un estado creativo y, por ende, el cuerpo, pues la apertura entre estos niveles hace que el actor conecte en sí mismo. 


\section{- Consciencia de los puntos energéticos del cuerpo}

El actor debe tomar consciencia de varios puntos energéticos y lograr una alineación entre éstos, para posteriormente explorar movimientos que rompan conscientemente con dicha alineación. Para esto suele recurrirse a dos líneas: en primer lugar, la de la columna, que va del cóccix a la coronilla, enfocándose con las rodillas ligeramente flexionadas y los pies en paralelo a la altura de los hombros, buscando que el cóccix conecte con la tierra y la coronilla con el cielo, creando así una oposición entre dos fuerzas. Ésta suele ser la posición inicial en distintas modalidades de training, pero no la única que puede servir como punto de partida para la creación. Si bien se busca una alineación para el reconocimiento del cuerpo, es la consciencia de la misma la que posibilita romperla después. El actor debe buscar variaciones y probar distintas posiciones, dependiendo de a dónde quiera llegar o el camino que vaya tomando la exploración. Saber elegir esto requiere de mucha auto-observación en el training.

La segunda línea de la cual el actor debe tomar consciencia es la central o frontal que inicia en la frente, pasa por la nariz, la garganta, el esternón, baja por el ombligo y llega hasta el hara, para después seguir descendiendo hasta el perineo (puntos que coinciden con los chacras del yoga). Según Yoshi Oida, "sin conexión interna con el hara, el exterior de un actor no puede funcionar correctamente. Por lo tanto, antes de que los actores realicen cualquier acción extraordinaria, deben conectarse con el hara y proceder desde ahí" (Los trucos del actor 22). Esta segunda línea crea la consciencia en el actor de sus lados izquierdo y derecho, de este modo se mantiene una relación entre ambas partes. El hecho de estar así alineado hace que el actor aprenda de una manera más efectiva y que pueda crear movimiento y personajes a partir de una mayor consciencia de su cuerpo.

\section{- Masaje y respiración para la disposición en el training}

El masaje se emplea en el butoh para generar una mayor disposición. Por su parte, la respiración acompaña cada movimiento del masaje, calentamiento y danza. En Japón, y en Asia en general, existe una cultura muy arraigada del cuidado del cuerpo en este sentido. El masaje se puede realizar al inicio o al final de cada sesión de trabajo, hay diversos tipos que sirven para distintos fines (unos para la relajación estática, otros permiten una relajación más activa, mientras que las variaciones en la respiración direccionan la intención de cada recurso). Al inicio de una sesión, el masaje sirve para despertar al músculo y para que las terminales nerviosas se relajen y conecten; forma parte de la limpieza de bloqueos que se busca continuamente. Como ejemplo, dice Yoshi Oida que: "una de las maneras de preparar y reforzar el hara es aplicándole un masaje, pues, paradójicamente, un hara 'fuerte' es suave y maleable" (El actor invisible 41). 
Después se realizan estiramientos, ya sea para destensar un músculo, para relajar el cuerpo en un estado pasivo o para despertarlo y generar una activación (se debe poner atención en el objetivo específico para saber qué tipo de estiramiento conviene en cada caso). El movimiento, junto con la respiración, genera un estado de concentración y conexión cuerpo-mente que ayuda en la profundización de la investigación a lo largo de cada sesión del training.

\section{- Honestidad: lenguaje propio}

Se suele malinterpretar que cualquier forma extraña y bizarra puede ser considerada butoh, pero en realidad este arte no busca generar una forma externa carente de sustancia. Hijikata estaba en total desacuerdo con el uso de formas preestablecidas o ególatras, y esta idea fue heredada por todos sus discípulos y los actuales creadores que viven de sus enseñanzas. En el butoh, la sustancia, la esencia, la imagen y el cuerpo nacen y se crean de modo indisociable, no con la finalidad de hacer algo extraño (lo que sería una intención del ego), sino con la de danzar a través del cuerpo y no meramente con el cuerpo.

Katsura Kan, el discípulo de Hijikata, menciona:

La esencia del Butoh es el descubrimiento acerca de lo que es el cuerpo. La técnica es importante, pero lo que el Butoh nos muestra es que hay cosas más importantes que la técnica, qué es lo que está adentro de tu realidad y cómo la expresas. La realidad es lo más importante. Mediante el Butoh puedes mostrarla, es decir, no muestras algo por medio del cuerpo sino lo que el cuerpo mismo es (citado en Segura 46).

En marzo de 2014, Katsura Kan impartió un taller en Xalapa. Allí insistió en que se debe buscar un lenguaje propio en el movimiento, de manera que éste sea interno, creando un paisaje y una atmósfera en la danza o el teatro. Más que un virtuosismo, se busca que el cuerpo logre un movimiento honesto que produzca en el público una conexión con lo que ve (transmitiendo, perturbando y generando un estado fuera de lo cotidiano).

Si bien cada creador de butoh desarrolla su propia danza y su propia definición de lo que es este género, lo importante es la congruencia interna con lo que se está haciendo, pues no es lo mismo moverse de manera inconexa -apartado de uno mismo- que estar profundamente conectado y en un amplio nivel de percepción con uno y con el entorno. La relación entre cuerpo e imagen es sumamente importante en cualquier movimiento y acción sobre la escena, pues genera transformación en el actor y en el público, tal como busca el butoh. 
INVESTIGACIÓNTEATRAL

Revista de artes escénicas y performatividad

Vol. 10, Núm. 16

octubre 2019-marzo 2020
La exploración de un training cuerpo-mente del actor a través del butoh

María Angélica Zamora Chong

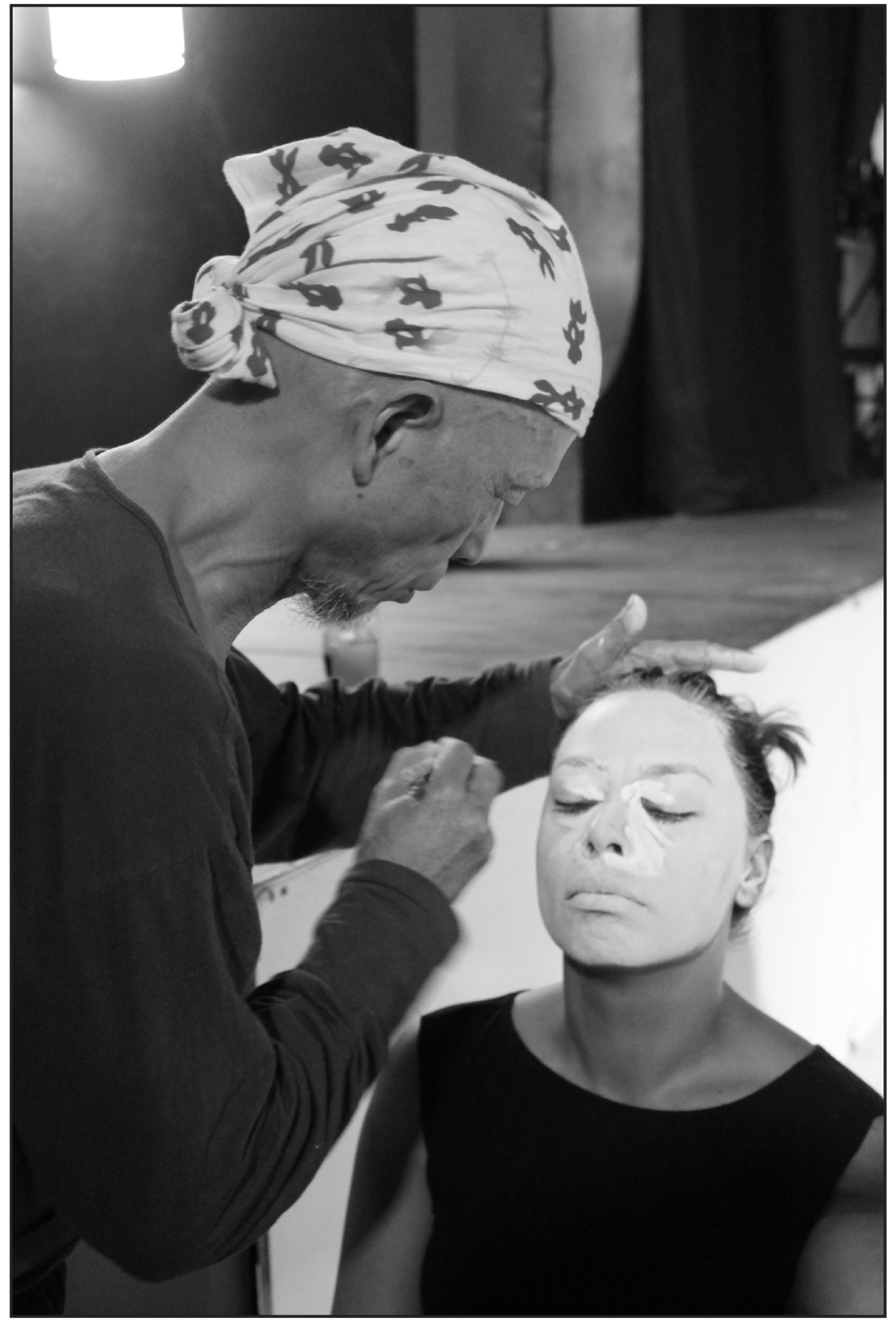

Katsura Kan aplicando el maquillaje de arroz tradicional en el butoh, previo a la presentación final del workshop. Teatro La Libertad, Xalapa, 2014. Fotografía de Angélica Zamora Chong.

- Improvisación, tiempo y ritmo: eternidad

Desde Tatsumi Hijikata y Kazuo Ohno, se generaron dos grandes vertientes en el butoh: mientras que el primero se preocupó por sentar algunas bases ideológicas y artísticas, poniendo atención en lo técnico (pues concebía al butoh como teatro y modo de vida), el se- 
gundo tendió más a la vía de la improvisación y lo conceptual. Todos sus alumnos directos, y los que en subsiguientes generaciones recibieron sus propuestas -se les llama algunas veces butokas - han adoptado y hecho suyas tales vertientes. Katsura Kan y Yumiko Yoshioka son ejemplos de la combinación de los legados de Ohno e Hijikata.

La improvisación es un elemento fundamental en el butoh, pero no equivale en este contexto a hacer "cualquier cosa", sino que implica un conocimiento y se genera a partir de una coherencia con el ambiente, la imagen, y el cuerpo. Este tipo de improvisación requiere que el intérprete maneje un tema e investigue continuamente, hasta que se vuelve tan perfecta su exploración que parezca ensayada, pues también implica precisión. Se busca una variación en el manejo del ritmo, en las diversas calidades de movimiento, y en mover el espacio y el tiempo. Ko Murobushi, otro alumno directo de Tatsumi Hijikata, afirma al respecto:

El cuerpo debe atacar la eternidad. Creo que se puede concentrar la eternidad en un solo momento. Entonces el cuerpo se vuelve eterno y atestiguar eso es fuerte... Yo también estoy cambiando constantemente junto con mi cuerpo y tampoco soy sólo mi cuerpo, soy las combinaciones de mí con las demás personas en el espacio y el tiempo (citado en Segura 26-27).

El butoh se mueve en un espacio sin un tiempo medible; sólo hay momentos, instantes eternos. En cuanto al ritmo, se busca que el espectador no se acostumbre a él, que resulte impredecible lo que va a suceder sobre el escenario. El silencio es un elemento fundamental para lograr esto, pues el ruido hace que la danza se vuelva predecible. Se busca un estado de inmovilidad activa, donde se pueda ver al cuerpo flotar y sólo estar. La auto-exploración del actor, a través del manejo de diversas calidades de movimiento y de los instantes eternos, genera un instrumento tremendamente sensible y capaz de tener una conexión impresionante consigo mismo. Pero, más allá de un virtuosismo calificativo, el conocimiento de estos elementos en el training genera un enriquecimiento en las acciones de toda la puesta en escena.

\section{Conclusión}

El butoh ha evolucionado en la historia, junto con la vida y los cuerpos. Los motivos para generar vida en la escena se desarrollan, modifican, apropian o sanan, y así se generan nuevos incentivos. El butoh es una expresión universal del cuerpo y de la mente, que en el training de los actores es capaz de generar un intenso y profundo auto-conocimiento. Da libertad y 
consciencia de los recursos que se tienen y de las propias capacidades, con lo cual el actor adquiere herramientas expresivas extraordinarias. El butoh posibilita un regreso al origen, ante la confrontación constante de bloqueos que solamente estorban a la creación y al auto-conocimiento (como el ego, los falsos juicios o conceptos impuestos). Éstos deben disolverse, ya que pueden volverse muy peligrosos a la hora de crear y vivir la escena. No hay una verdad absoluta, quizá la única verdad sea la coherencia con uno mismo. Eso es libertad.

En el training a partir del butoh, el actor tiene la oportunidad de conocer sus posibilidades, indagar en todo lo que puede lograr y valorar cada momento de la auto-exploración. Esto genera una evolución en el actor, quien está en constante cambio y crecimiento. Por eso el training es un camino de toda la vida, pues el cuerpo está en transformación y el actor no debe perder de vista esto, sino estar muy atento de lo que le ocurre como persona, actor y personaje.

Los actores que profundizan y trabajan el cuerpo y la mente a través de un training, pueden tener mayor presencia, ser más flexibles y, por ende -a la hora de trabajar sobre una puesta en escena-, podrán alcanzar un mayor conocimiento de sí mismos. Esto se consigue por medio de la investigación constante y disciplinada, a través del training, que permita el conocimiento de las capacidades propias (donde radicará la fuerza expresiva). El actor tiene la posibilidad de emprender, así, un maravilloso camino, construido de momentos, de instantes eternos que permanecerán en el tiempo, y donde el teatro -que es tan frágil y efímero, y a la vez tan potente y sensible- podrá permanecer a través de la entrega de este actor en su camino.

\section{Fuentes consultadas}

Artaud, Antonin. El teatro y su doble. Querétaro: Best Seller, 2006.

Barba, Eugenio y Nicola Savarese. El arte secreto del actor. Diccionario de antropología teatral. Ciudad de México: Escenología, 2002.

Blakeley, Susan. Ankoku Butoh. The Premodern and Postmodern Influences on the Dance of Utter Darkness. Nueva York: Cornell University, 1988.

Bremser, Martha, compiladora. Fifty Contemporary Choreographers. Londres: Routledge, 1999.

Cuerpos en Revuelta. "Festival". Cuerpos en Revuelta, Festival Internacional de Danza Butoh en América Latina Cuerpos en Revuelta, www.chopo.unam.mx/CuerposRevuelta/CuerposenRevuelta.html, consultado el 31 de julio de 2019.

Dance of Darkness. Dirigido por Edin Velez, con entrevistas a Tatsumi Hijikata, Mark Hol- 
burn, Akiko Motofuji, Kazuo Ohno, Isamu Ohsuga. Electronic Arts Intermix/Tapestry International/Museum of Modern Art, 1989.

Fibutoh. "Compañía Ruta de la Memoria (Santiago)". 3 ғівUтон, Festival Internacional Butoh Chile 2018, www.fibutoh.com/compania-ruta-de-la-memoria-2/, consultado el 31 de julio de 2019.

Gómez, Eirinet. "Falleció Rocío Sagaón, destacada bailarina, coreógrafa, escultora y actriz". La Jornada, 18 de agosto de 2015, www.jornada.com.mx/2015/08/18/cultura/a06n1 cul, consultado el 31 de julio de 2019.

Grotowski, Jerzy. Hacia un teatro pobre. Traducido por Margo Glantz. Ciudad de México: Siglo Veintiuno Editores, 2000.

Katsura, Kan. "Katsura Kan: Butoh Dancer" (entrevista). Kyoto Journal, 13 de agosto de 2011, kyotojournal.org/culture-arts/katsura-kan-butoh-dancer/, consultado el 7 de mayo de 2019.

Kisselgoff, Anna. "Dance View. Dai Rakuda Kan's Theater of Raw Images”. The New York Times, 19 de abril de 1987, www.nytimes.com/1987/04/19/arts/dance-view-dai-rakuda-kan-s-theater-of-raw-images.html, consultado el 7 de mayo de 2019.

Lizarazo, María Camila. "Lo grotesco en el Butoh: recobrando una humanidad perdida". Artes Escénicas de Japón,_www.japonartesescenicas.org/danza/generos/contemporanea/butoh/grotesco8.html, consultado el 7 de mayo de 2019.

MaGee, Chris. "Criminal Dance: The Early Films of Butoh Master Tatsumi Hijikata”. Midnight Eye. Visions of Japanese Cinema, 30 de septiembre de 2010, www.midnighteye. $\mathrm{com} /$ features/criminal-dance-the-early-films-of-butoh-master-tatsumi-hijikata/, consultado el 7 de mayo de 2019.

Maro, Akaji. "Entrevista con Jun-ichi Konuma”. Performing Arts Network Japan, 17 de junio de 2005, performingarts.jp/E/art_interview/0506/1.html, consultado el 7 de mayo de 2019.

Maro, Akaji. "Entrevista con Maro Akaji, director de la Cia. Dairakudakan Temptenshiki". YouTube, subido por DanzaNet TV, 30 de octubre de 2012, www.youtube.com/watch?v=m7t7PVmMdLE, consultado el 7 de mayo de 2019.

Morales, Sonia. “Concluyó el Cervantino”. Proceso, 16 de mayo de 1981, www.proceso.com. $\mathrm{mx} / 131061 /$ concluyo-el-cervantino, consultado el 26 de julio de 2019.

Moscovich, Laura. Entrevista personal. 9 de mayo de 2015.

Féral, Josette. “¿Dijo usted training?”. El training del actor, compilado por Carol Müller, traducido por María Dolores Ponce G. Ciudad de México: Conaculta, 2009, pp. 13-27.

Nakajima, Natsu. "Ankoku Butoh. La espiritualidad femenina en el teatro, la ópera y la danza" (ponencia). Octubre de 1997, Universidad Fu Jen, Taipei. Ponencia, traducida por Noemí Brickman. 
INVESTIGACIÓNTEATRAL

Revista de artes escénicas y performatividad

Vol. 10, Núm. 16

octubre 2019-marzo 2020
La exploración de un training cuerpo-mente del actor a través del butoh

María Angélica Zamora Chong

Oceransky, Abraham. Entrevista personal. 23 de mayo de 2015.

Oida, Yoshi. El actor invisible. Traducido por Elena Vilallonga. Barcelona: Alba Editorial, 2010.

Oida, Yoshi. Los trucos del actor. Traducido por Elena Vilallonga. Barcelona: Alba Editorial, 2010.

Segal, Lewis. "Dance Vision of Deformity, Illness, Anarchy, Despair: Dai Rakuda Kan In 'The Five Rings"'. Los Angeles Times, 4 de abril de 1987, www.latimes.com/archives/ la-xpm-1987-04-04-ca-1132-story.html, consultado el 7 de mayo de 2019.

Segura, Johana y Fabián Guerrero, editores. La eternidad en un instante, la danza butoh en voz de sus maestros. Ciudad de México: inFluir Ediciones, 2014.

"Muere Kazuo Ohno, referente cultural desde el arte dancístico". La Jornada, 3 de junio de 2010, www.jornada.com.mx/2010/06/03/cultura/a03n1cul, consultado el 26 de julio de 2019. 